\title{
PENGARUH KINERJA TERHADAP LAYANAN PRIMA DI CENTER OF INFORMATION SCIENTIFIC RESOURCES AND LIBRARY (CISRAL) UNIVERSITAS PADJAJARAN (Studi DEskriptif Terhadap Pemustaka Di Bagian Layanan Referensi CISRAL UNPAD)
}

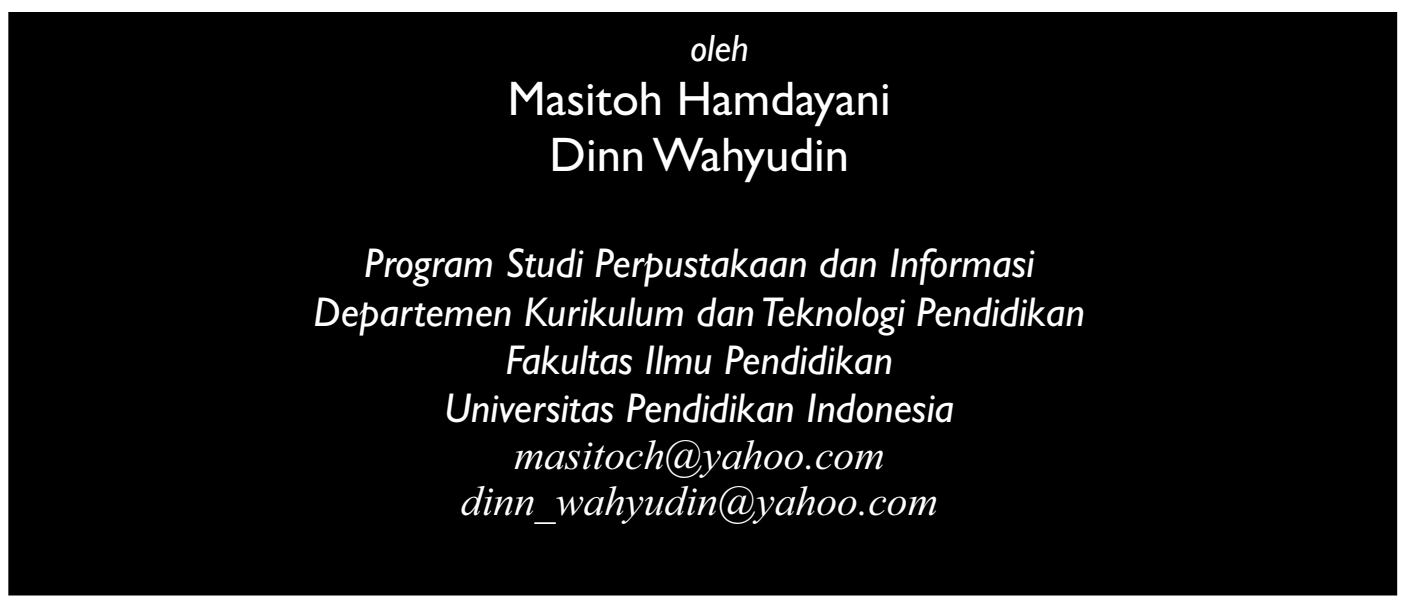

\begin{abstract}
ABSTRAK
Masalah yang menjadi kajian dalam penelitian adalah mengenai layanan prima. Inti kajiannya difokuskan pada salah satu faktor yang dapat mempengaruhi layanan prima yaitu kinerja pustakawan. berdasarkan hal tersebut, pokok masalah yang diungkap dalam penelitian ini adalah bagaimana pengauh kinerja pustakawan terhadap layanan prima. Penelitian ini terdiri dari dua variabel yaitu kinerja pustakawan (X) dan layanan prima (Y). kinerja pustakawan diukur melalui indikator karakteristik tingkah laku (behavioral characteristics), pengetahuan (knowledge), dan kemampuan dalam memberikan layanan referensi (reference skill). Layanan prima diukur melalui indikator bukti nyata (tangibles), reliabilitas (reliability), daya tanggap (responsiveness), jaminan (assurance), dan empati (empathy). Metode penelitian yang digunakan adalah studi deskriptif dengan pendekatan kuantitatif. Teknik pengumpulan data menggunakan kuesioner tertutup dengan skala lima kategori Likert dan menggunakan analisis data korelasi dan regresi.Populasi pada penelitian ini adalah pemustaka di bagian layanan referensi CISRAL UNPAD yaitu berjumlah 121 orang. Sampel yang diambil adalah berjumlah 55 orang berdasarkan rumus Slovin dengan metode penarikan sampel yaitu sampling insidental. Berdasarkan hasil penelitian, diketahui bahwa kinerja pustakawan mempunyai tingkat hubungan yang kuat dan berpengaruh signifikan terhadap layanan prima, dengan besarnya pengaruh sebesar.
\end{abstract}

Kata kunci: Kinerja, Pustakawan, Layanan Prima. 


\section{PENDAHULUAN}

Gudang buku dengan penataan dan pengelolaan asal-asalan yang ditempatkan di sudut ruangan merupakan pencintraan perpustakaan yang terekam pada surat kabar Kompas Senin, 19 November 2007 (Suherman, 2009: 7). Perpustakaan yang identik dengan buku sering didefinisikan sebagai sebuah ruangan atau gedung yang digunakan untuk menyimpan buku dengan susunan tertentu. Perpustakaan tidak hanya sekedar ruangan atau gedung yang menyimpan buku, tetapi merupakan suatu organisasi yang terus berkembang (a library is a growing organism) sesuai dengan berkembangnya ilmu pengetahuan dan teknologi yang didalamnya terdapat lima elemen pendukung, yaitu: "perpustakaan, pustakawan, informasi, koleksi, dan pemustaka" (Suherman, 2011: 7). Perpustakaan merupakan sebagai salah satu penunjang proses pembelajaran. Pada perguruan tinggi keberadaan perpustakaan sangat membantu mahasiswa dan civitas akademika dalam mencari informasi dan menyelesaikan tugas-tugas perkuliahan. "Perpustakaan perguruan tinggi ialah perpustakaan yang terdapat pada perguruan tinggi, badan bawahannya, maupun lembaga yang berafiliasi dengan perguruan tinggi..." (Basuki, 1993: 51). Perpustakaan perguruan tinggi bertujuan untuk mendukung pelaksanaan Tri Dharma perguruan tinggi yang terdiri dari pendidikan, penelitian dan pengabdian masyarakat.

Perpustakaan perguruan tinggi memberikan layanan untuk menunjang kegiatan belajar mengajar dan memenuhi kebutuhan pemustakanya. Layanan yang umum diberikan perpustakaan perguruan tinggi kepada para pemustaka menurut Departemen Pendidikan Nasional RI (2004: 71) adalah "layanan sirkulasi, layanan rujukan/referensi, layanan multimedia, jasa kesiagaan informasi, pendidikan pengguna, dan silang layang." Layanan yang tersedia di perpustakaan perguruan tinggi diharapkan mampu memenuhi kebutuhan pemustakanya. Untuk dapat memberikan layanan yang baik kepada para pemustaka diperlukan pustakawan yang handal, karena sosok pustakawan akan dapat memberikan pencitraan terhadap perpustakaan. Menurut
Undang-Undang Nomor 43 Tahun 2007 Pasal 1 tentang Perpustakaan, disebutkan bahwa "pustakawan adalah seseorang yang memiliki kompetensi yang diperoleh melalui pendidikan dan/atau pelatihan kepustakawanan serta mempunyai tugas dan tanggung jawab untuk melaksanakan pengelolaan dan pelayanan perpustakaan."

Pustakawan yang handal diharapkan dapat memberikan layanan yang baik melalui pelayanan prima kepada para pemustaka agar pemustaka menjadi loyal terhadap perpustakaan sehingga koleksi, fasilitas dan layanan yang tersedia dapat dimanfaatkan dengan baik. Hal ini sesuai dengan UndangUndang Nomor 43 Tahun 2007 Pasal 32 tentang Perpustakaan, yang menyatakan bahwa "tenaga perpustakaan berkewajiban memberikan layanan prima terhadap pemustaka." Layanan prima akan terwujud bila pustakawan menunjukan kinerja yang baik. Kinerja pustakawan sangat menunjang dalam memberikan layanan kepada pemustaka, karena pustakawan yang memiliki kinerja yang baik akan senantiasa memiliki komitmen untuk memberikan layanan prima kepada pemustakanya.

Berdasarkan hal tersebut peneliti ingin membuktikan apakah pada perpustakaan perguruaan tinggi, khususnya perpustakaan CISRAL UNPAD, kinerja pustakawan dalam memberikan pelayanan kepada pemustaka memiliki pengaruh terhadap layanan prima di perpustakaan. Dan umusan masalah umum yang akan diteliti adalah "Bagaimana pengaruh kinerja pustakawan terhadap layanan prima di CISRAL UNPAD" dengan rumusan masalah khusus, yaitu bagaimana gambaran kinerja pustakawan di bagian layanan referensi CISRAL UNPAD dan bagaimana gambaran layanan prima di bagian layanan referensi CISRAL UNPAD.

Peneliti memiliki beberapa tujuan yang hendak dicapai dalam penelitian. Tujuan penelitian yang dimaksud adalah untuk mengetahui pengaruh antara kinerja pustakawan terhadap layanan prima di CISRAL UNPAD, untuk mengetahui gambaran kinerja pustakawan di bagian layanan referensi CISRAL UNPAD, dan untuk mengetahui gambaran layanan prima di bagian layanan referensi CISRAL UNPAD.

Dari penelitian ini, peneliti berharap 
mendapatkan manfaat baik bagi peneliti sendiri, objek penelitian dan pembaca. Secara teoritis penelitian ini diharapkan dapat memberikan manfaat untuk penelitianpenelitian yang berhubungan dengan kinerja pustakawan dalam melakukan layanan prima dan bagi perkembangan ilmu perpustakaan dan informasi di bidang layanan dan kinerja pustakawan. Dan secara praktis penelitian ini diharapkan dapat memberi masukan bagi pustakawan dan CISRAL UNPAD dalam memberikan layanan prima bagi pemustaka agar koleksi dan fasilitas yang telah disediakan dapat dimanfaatkan.

\section{PEMBAHASAN}

Perpustakaan perguruan tinggi merupakan unsur penunjang yang bersamasama dengan unsur penunjang lainya, berperan serta dalam melaksanakan tercapainya visi dan misi perguruan tinggi. Menurut Basuki (1993: 51) "perpustakaan perguruan tinggi ialah perpustakaan yang terdapat pada perguruan tinggi, badan bawahannya, maupun lembaga yang berafiliasi dengan perguruan tinggi..." Adapun tugas perpustakaan perguruan tinggi menurut Departemen Pendidikan Nasional RI (2004: 3) adalah "mengambangkan koleksi, mengolah dan merawat bahan pustaka, memberi layanan, serta melaksanakan administrasi perpustakaan." Tugas-tugas tersebut dilaksanakan dengan sistem administrasi dan organisasi yang berlaku bagi penyelenggaraan sebuah perpustakaan di perguruan tinggi.

Pustakawan sebagai salah satu motor penggerak perpustakaan dalam melakukan pelayanan kepada pemustaka perlu menunjukan kinerja yang baik dan dapat memuskan kebutuhan informasi pemustaka sehingga layanan prima dapat tercapai. Layanan prima (excellent service) mengacu pada layanan yang memenuhi atau bahkan melampaui harapan pelanggan atau pengguna jasa. Menurut Barata dalam Achmad et al. (2012: 80) mendefinisikan bahwa "layanan prima adalah membuat pelanggan merasa penting." Prinsip pokok mewujudkan layanan prima menurut Marknesis (2009: 105) adalah "doing best what matters most to customers." Layanan prima harus dimulai dari kebutuhan pelanggan dan berakhir dengan kepuasan pelanggan serta persepsi positif terhadap kualitas layanan. Hal ini sejalan dengan Undang-Undang Nomor 43 Tahun 2007 Pasal 32 Ayat a tentang Perpustakaan, bahwa "tenaga perpustakaan berkewajiban memberikan layanan prima terhadap pemustaka." Hal penting yang perlu diperhatikan dalam memberikan layanan prima adalah dimensi kualitas jasa/layanan. Kualitas jasa/layanan yang dikelola dengan tepat akan berkontribusi positif terhadap terwujudnya kepuasan dan loyalitas pemustaka. Banyak diantara klasifikasi rumusan dimensi kualitas jasa/layanan yang mirip satu sama lain, hanya berbeda istilahnya saja, tetapi menurut Tjiptono (2012: 172) "yang paling banyak diacu dalam pengukuran kinerja layanan/jasa adalah dimensi kualitas layanan versi Parasuraman, Zeithaml dan Berry (1988)." Dan untuk mengetahui kinerja yang telah dilakukan oleh pustakawan perlu adanya evaluasi. Menurut Stufflebeam et al. dalam Daryanto (2007: 1) evaluasi adalah “...the process of delineating, obtaining, and providing useful information for judging decision alternatives." Dengan melakukan evaluasi kinerja, pustakawan dapat mengetahui keberhasilan tujuan yang telah dicapai dan yang belum tercapai, serta dapat memperbaiki kesalahan atau meningkatkan kinerjanya.

Reference/Information Services Department di Alfred Taubman Medical Library (TML) telah mengembangkan standar untuk mengevaluasi kinerja pustakawan referensi yang akan membantu perkembangan tingkat layanan dan tingkah laku profesional yang seragam. Standar tersebut menurut Schwartz dalam Sulistyorini (2004: 26) kemudian dijabarkan ke dalam tiga kategori, yaitu "karakteristik tingkah laku (behavioral characteristics), pengetahuan (knowledge) dan kemampuan dalam memberikan layanan referensi (reference skill)."

Adapun teori yang mendukung penelitian ini adalah dimensi kualitas layanan versi Parasuraman, Zeithaml dan Berry (1988) dan standar untuk mengevaluasi kinerja pustakawan referensi menurut Schwartz yang telah dijelaskan pada uraian di atas.

Populasi yang diteliti pada penelitian 
ini adalah seluruh pemustaka di bagian layanan referensi CISRAL UNPAD di bulan Maret tahun 2013 yaitu sebanyak 121 pemustaka. Taknik pengambilan sampel yang digunakan adalah sampling insidental. Adapun dalam menentukan besaran sampel peneliti menggunakan rumus Slovin (Noor, 2011: 158) dengan tingkat kesalahan $10 \%$ sehingga sampel yang didapat adalah sebanyak 55 orang. Metode yang digunakan dalam penelitian ini adalah metode penelitian deskriptif dengan pendekatan kuantitatif. Metode ini digunakan karena penelitian ini ingin membuktikan pengaruh kinerja pustakawan terhadap layanan prima di CISRAL UNPAD. Karena kedua variabel ini dapat diukur, maka peneliti menggunakan pendekatan kuantitatif dengan menggunakan perhitungan matematis dan kuesioner sebagai media pengumpulan data penelitian.

Hasil penyebaran kuesioner dan penelitian yang telah dilakukan maka diperoleh data hasil perhitungan berikut.

Hasil perhitungan koefisien korelasi menggunakan rumus Pearson/Product Moment (Sundayana, 2010: 200) untuk mengetahui besarnya pengaruh/hubungan antara variabel bebas (X) dengan variabel terikat (Y) adalah sebagai berikut:

$$
\begin{aligned}
& \mathrm{r}_{\mathrm{xy}}= \\
& \frac{(55)(6536.636)-(0.00)(0.00)}{\sqrt{\left\{(55)(14614.417)-(0.00)^{2}\right\} \cdot\left\{(55)(6106.560)-(0.00)^{2}\right\}}} \\
& \mathrm{r}_{\mathrm{xy}}=\frac{359514.959}{\sqrt{\{803792.912\} \cdot\{335860.796\}}} \\
& \mathrm{r}_{\mathrm{xy}}=\frac{359514.959}{\sqrt{269962526764.105}} \\
& \mathrm{r}_{\mathrm{xy}}=\frac{359514.959}{519579.182} \\
& \mathrm{r}_{\mathrm{xy}}=0.692
\end{aligned}
$$

Berdasarkan hasil perhitungan di atas menunjukan bahwa koefisien korelasi antara dua variabel adalah sebesar 0.692 , bila diinterpretasikan pada tabel menurut Sugiyono (2012: 184) maka tingkat hubungan antara variabel kinerja pustakawan dengan layanan prima memiliki hubungan yang kuat. Setelah diketahui besarnya koefisien korelasi antara dua variabel, kemudian di uji keberartiannya, apakah koefisien korelasi yang dihasilkan signifikan atau tidak, dan uji yang digunakan adalah menggunakan uji t (Sundayana, 2010: 200).

$$
\begin{aligned}
& \mathrm{t}_{\text {hitung }}=\frac{0.692 \sqrt{55-2}}{\sqrt{1-0.692^{2}}} \\
& \mathrm{t}_{\text {hitung }}=\frac{0.692 \sqrt{53}}{\sqrt{1-0.479}} \\
& \mathrm{t}_{\text {hitung }}=\frac{(0.692) \cdot(7.280)}{\sqrt{0.521}} \\
& \mathrm{t}_{\text {hitung }}=\frac{(0.692) \cdot(7.280)}{0.722} \\
& \mathrm{t}_{\text {hitung }}=\frac{5.038}{0.722} \\
& \mathrm{t}_{\text {hitung }}=6.978
\end{aligned}
$$

Berdasarkan hasil dari perhitungan uji $\mathrm{t}$ menunjukan bahwa $t_{\text {hitung }}$ adalah 6.978 dan $\mathrm{t}_{\text {tabel }}$ adalah 2.007. Bila dimasukan kedalam kriteria pengujian maka:

$t_{\text {hitung }}=6.978>t_{\text {tabel }}=2.007$ maka $_{0}$ ditolak dan $\mathrm{H}_{1}$ diterima. Adapun hipotesis dari penelitian ini yaitu:

- $\mathrm{H}_{0}$ : Kinerja pustakawan tidak mempunyai pengaruh yang signifikan terhadap layanan prima di CISRAL UNPAD.

- $\mathrm{H}_{1}$ : Kinerja pustakawan mempunyai pengaruh yang signifikan terhadap layanan prima di CISRAL UNPAD.

Berdasarkan kriteria pengujian tersebut, hasil perhitungan menunjukan bahwa kinerja pustakawan mempunyai pengaruh yang signifikan terhadap layanan prima di CISRAL UNPAD. Jika hasil dari pengujian koefisien korelasi menghasilkan korelasi yang signifikan, maka besarnya pengaruh antar variabel dapat dicari dengan koefisien determinasi (Sundayana, 2011: 201). Hasil perhitungan koefisien determinasi adalah sebagai berikut:

$5 \square$ × 100\%

$\mathrm{D}=47.9 \% \quad$ dibulatkan menjadi $48 \%$

Bedasarkan hasil perhitungan koefisien determinasi di atas, menunjukan bahwa nilai koefisien determinasi adalah sebesar $48 \%$. Hal tersebut menunjukan bahwa besarnya pengaruh antara variabel kinerja pustakawan dengan variabel layanan prima adalah sebesar $48 \%$. 
Tabel Kesimpulan Hasil Penelitian

\begin{tabular}{|c|c|c|c|c|c|c|c|}
\hline Peagujian & Hent & $\mathrm{I}_{\mathrm{at}: \mathrm{A}}$ & a & \multicolumn{2}{|c|}{ Krittrí } & \multicolumn{2}{|r|}{ Keteragan } \\
\hline$X \rightarrow Y$ & 0.692 & 0271 & $\begin{array}{c}50,2 \pi \\
0.03 \\
d=0.2 \\
(3 j)\end{array}$ & $\begin{array}{c}f_{\text {bitm }}> \\
f_{b i}\end{array}$ & $\begin{array}{l}\text { Tatike } \\
\text { thagen } \\
\text { yeg bue }\end{array}$ & $\begin{array}{c}\mathrm{H}_{\mathrm{j}} \text { dinlak } \\
\text { dan } \\
\text { dermi }\end{array}$ & 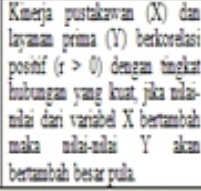 \\
\hline Peagujan & thing & $t_{t|x|}$ & a & \multicolumn{2}{|c|}{ Kritenia } & \multicolumn{2}{|r|}{ Keterngan } \\
\hline$X \rightarrow Y$ & 6978 & 2007 & $\begin{array}{c}50,25 \\
0.03 \\
d=0-2 \\
(5 j)\end{array}$ & $\begin{array}{l}t_{\text {thag }}> \\
t_{\text {ini }}\end{array}$ & Sigifia & $\begin{array}{l}\text { H, dinlak } \\
\text { don } \mathrm{H}_{\text {? }} \\
\text { derma }\end{array}$ & 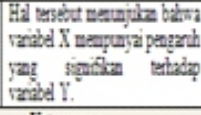 \\
\hline Peagujan & \multicolumn{2}{|c|}{ Ming } & $r^{2}$ & & D & \multicolumn{2}{|c|}{ Ketmagan } \\
\hline$X \rightarrow Y$ & \multicolumn{2}{|c|}{0.692} & 0.49 & \multicolumn{2}{|c|}{$45 \%$} & \multicolumn{2}{|c|}{ 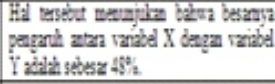 } \\
\hline Peagujan & $a$ & $\beta$ & \multicolumn{3}{|c|}{ Penamman Regresi } & \multicolumn{2}{|c|}{\begin{tabular}{|c|} 
Ketenugan \\
\end{tabular}} \\
\hline$X \rightarrow Y$ & 0.000 & 0.47 & \multicolumn{3}{|c|}{$\hat{Y}=0.000-0.47(I)$} & \multicolumn{2}{|c|}{ 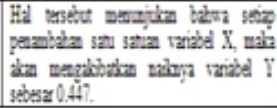 } \\
\hline
\end{tabular}

Permasalahan yang ingin dijawab adalah "bagaimana pengaruh kinerja pustakawan terhadap layanan prima di CISRAL UNPAD." Setelah peneliti melakukan analisis data dan melakukan uji normalitas, diketahui bahwa data pada variabel $\mathrm{X}$ dan variabel $\mathrm{Y}$ berdistribusi normal, maka peneliti menggunakan statistik parametrik dalam menguji hipotesis penelitian. Pengujian hipotesis dilakukan untuk menjawab hipotesis penelitian yang telah dirumuskan pada bab dua dan untuk menarik kesimpulan mengenai ada atau tidaknya pengaruh kinerja pustakawan terhadap layanan prima di CISRAL UNPAD. Berdasarkan hasil perhitungan regresi diperoleh hasil persamaan regresi linier $\ddot{A}=0.000+0.447(\mathrm{x})$. Hal ini menunjukan bahwa nilai b adalah sebesar 0.477 . Nilai konstanta 0.000 dapat diartikan bahwa layanan prima bernilai 0.000 jika tidak ada kinerja pustakawan yang baik, tetapi jika ada kinerja pustakawan yang baik maka layanan prima di CISRAL UNPAD akan meningkat sebesar 0.477 . Jika terdapat peningkatan pada variabel bebas (kinerja pustakawan), maka terdapat pula peningkatan pada layanan prima sebesar 0.447 . Perubahan ini menunjukan adanya peningkatan karena bernilai b positif. Dan nilai koefisien determinasi pada varibel kinerja pustakawan terhadap layanan prima sebesar $48 \%$, hal ini berarti bahwa layanan prima dipengaruhi oleh kinerja pustakawan sebesar $48 \%$, sedangkan sisanya sebesar $52 \%$ dipengaruhi oleh faktor lain yang tidak diteliti pada penelitian ini.

Permasalahan yang ingin dijawab adalah "bagaimana gambaran kinerja pustakawan di bagian layanan referensi CISRAL UNPAD." Kinerja pustakawan merupakan hasil pekerjaan yang mempunyai hubungan kuat dengan tujuan strategis organisasi dan kepuasan pemustaka. Kinerja pustakawan dalam memberikan pelayanan di perpustakaan dapat langsung dirasakan ketika pustakawan melayani pemustaka yang datang. Melalui pelayanan yang diberikan pemustaka dapat menilai apakah kinerja pustakawan dalam memberikan pelayanan di perpustakaan dapat memuaskan kebutuhan pemustaka atau tidak. Gambaran mengenai kinerja pustakawan berdasarkan hasil penelitian menunjukan bahwa 55 orang responden memilih alternatif jawaban setuju (skor 4), yaitu sebanyak 851 frekuensi atau $53 \%$ pada 29 pernyataan mengenai variabel $X$ (kinerja pustakawan), bila diinterpretasikan pada kriteria yang dikemukakan oleh Nugraha dalam Kartasasmita (2005: 107) maka 53\% termasuk dalam kategori rendah. Hasil penelitian tersebut menunjukan bahwa kinerja pustakawan di bagian layanan referensi CISRAL UNPAD mempunyai karakteristik tingkah laku, pengetahuan, dan kemampuan yang rendah dalam memberikan layanan rujukan.

Permasalahan yang ingin dijawab adalah "bagaimana gambaran layanan prima di bagian layanan referensi CISRAL UNPAD." Layanan prima mengacu pada layanan yang memenuhi atau bahkan melampaui harapan pemustaka. Manfaat layanan prima di perpustakaan adalah agar koleksi, fasilitas, dan jasa yang diberikan dapat dimanfaatkan secara maksimal oleh pemustaka. Dengan demikian aset perpustakaan yang cukup mahal dapat dimanfaatkan untuk meningkatkan kualitas hidup pemustaka dan megokohkan eksistensi perpustakaan tersebut. Gambaran mengenai layanan prima berdasarkan hasil penelitian, menunjukan bahwa 55 orang responden memilih alternatif jawaban setuju (skor 4), yaitu sebanyak 495 frekuensi atau $50 \%$ pada 18 pernyataan mengenai variabel Y (layanan prima), bila diinterpretasikan pada kriteria yang dikemukakan oleh Nugraha dalam Kartasasmita (2005: 107) maka 50\% termasuk dalam kategori rendah. Hasil penelitian tersebut menunjukan bahwa 
layanan prima di bagian layanan referensi CISRAL UNPAD mempunyai bukti nyata (tangibles), reliabilitas (reliability), daya tanggap (responsiveness), jaminan (assurance), dan empati (empathy) yang rendah.

Berdasarkan hasil tersebut, maka peneliti telah menjawab pertanyaan penelitian yang terdapat pada rumusan masalah, yaitu bagaimana pengaruh kinerja pustakawan terhadap layanan prima di CISRAL UNPAD.

\section{KESIMPULAN}

Kesimpulan ini berdasarkan hasil analisa statistik yang sesuai dengan rumusan masalah penelitian. Berdasarkan penelitian yang telah dilakukan diketahui bahwa kinerja pustakawan mempunyai pengaruh yang signifikan terhadap layanan prima di CISRAL UNPAD. Namun, layanan prima di CISRAL UNPAD tidak hanya dipengaruhi oleh faktor kinerja pustakawan saja, tetapi ada faktor lain yang juga berpengaruh, yang tidak dikaji pada penelitian ini.

Gambaran mengenai kinerja pustakawan yang diukur melalui indikator (1) karakteristik tingkah laku (behavioral characteristic), (2) pengetahuan (knowledge), dan (3) kemampuan dalam memberikan layanan rujukan (reference skill), yang berdasarkan hasil analisis data menunjukan bahwa kecenderungan jawaban responden berada pada skala setuju dengan skor empat dan bila dikategorikan termasuk ke dalam kategori rendah. Hasil penelitian tersebut menunjukan bahwa rendahnya kinerja pustakawan di bagian layanan referensi CISRAL UNPAD.

Gambaran mengenai layanan prima yang diukur melalui indikator (1) bukti nyata (tangibles), (2) reliabilitas (reliability), (3) daya tanggap (responsiveness), (4) jaminan (assurance), dan (5) empati (empathy), yang berdasarkan hasil analisis data menunjukan bahwa kecenderungan jawaban responden berada pada skala setuju dengan skor empat dan bila dikategorikan termasuk ke dalam kategori rendah. Hasil penelitian tersebut menunjukan bahwa rendahnya layanan prima di bagian layanan referensi CISRAL UNPAD.

\section{DAFTAR PUSTAKA}

Achmad. et al. (2012). Layanan Cinta: Perwujudan Layanan Prima ++ Perpustakaan. Jakarta: Sagung Seto.

Daryanto, H. (2007). Evaluasi Pendidikan. Jakarta: Rineka Cipta.

Marknesis, T. (2009). Customer Satisfaction and Beyond. Yogyakarta: Marknesis.

Noor, J. (2011). Metodologi Penelitian: Skripsi, Tesis, Disertasi, dan Karya Ilmiah. Jakarta: Kencana.

Sedarmayanti. (2009). Sumber Daya Manusia dan Produktivitas Kerja. Bandung: Mandar Maju.

Sugiyono. (2012). Metode Penelitian Kuantitatif, Kualitatif, dan $R \& D$. Bandung: Alfabeta.

Suherman. (2011). Pustakawan Inspiratif. Bandung: MQS Publishing.

Suherman. (2009). Perpustakaan sebagai Jantung Sekolah. Bandung: MQS Publishing.

Sulistyo-Basuki. (1993). Pengantar Ilmu Perpustakaan. Jakarta: Gramedia Pustaka Utama.

Sundayana, R. (2010). Statistika Penelitian Pendidikan. Garut: STKIP Garut Press.

Tjiptono, F. (2012). Service Management Mewujudkan Layanan Prima. Yogyakarta: Andi. Skripsi.

Kartasasmita, K. (2005). Kontribusi Fasilitas Perpustakaan dan Kinerja Pustakawan terhadap Kepuasan Pengguna di Universitas Pasundan. Tesis FIP UPI: Tidak Diterbitkan.

Sulistyorini, J. (2004). Persepsi Pemakai terhadap Karekteristik Tingkah Laku dan Kemampuan Pustakawan Rujukan dalam Memberikan Layanan Rujukan di UPT Perpustakaan IPB. Skripsi FIB UI: Tidak Diterbitkan.

Publikasi Departemen 
Departemen Pendidikan Nasional.

(2004). Perpustakaan Perguruan

Tinggi: Buku Pedoman Edisi Ketiga.

Jakarta: Depatemen Pendidkan

Nasional RI. Direktorat Jenderal

Pendidikan Tinggi.

Sumber Online

Perpustakaan Nasional Republik

Indonesia. (2007). Undang-Undang

Republik Indonesia Nomor 43 Tahun

2007 tentang Perpustakaan.

[Online]. Tersedia:

http://kelembagaan.pnri.go.id/Digita

1_Docs/homepage_folders/activities/

highlight/ruu perpustakaan/pdf/UU

43_2007_PERPUSTAKAAN.pdf

[21 Juni 2011]. 